\title{
Article
}

\section{In their own words: investigating the preparedness of final year dental students in the UK for independent general dental practice}

Ray, M, Milston, Anne Marie, Doherty, Paul William and Crean, Stjohn

Available at https://clok.uclan.ac.uk/24064/

Ray, M, Milston, Anne Marie orcid iconORCID: 0000-0002-7491-5639, Doherty, Paul William orcid iconORCID: 0000-0003-3463-9112 and Crean, Stjohn orcid iconORCID: 0000-0001-9336-8549 (2018) In their own words: investigating the preparedness of final year dental students in the UK for independent general dental practice. British Dental Journal, 225 (4). pp. 340-349. ISSN 0007-0610

It is advisable to refer to the publisher's version if you intend to cite from the work. http://dx.doi.org/10.1038/s..bdj.2018.646

For more information about UCLan's research in this area go to http://www.uclan.ac.uk/researchgroups/ and search for <name of research Group>.

For information about Research generally at UCLan please go to http://www.uclan.ac.uk/research/

All outputs in CLoK are protected by Intellectual Property Rights law, including Copyright law. Copyright, IPR and Moral Rights for the works on this site are retained by the individual authors and/or other copyright owners. Terms and conditions for use of this material are defined in the policies page. 


\section{IN THEIR OWN WORDS: INVESTIGATING THE PREPAREDNESS OF FINAL YEAR DENTAL STUDENTS IN THE UK FOR INDEPENDENT GENERAL DENTAL PRACTICE}

Ray M, Milston A, Doherty P, Crean S.

ABSTRACT.

Introduction.

There is relatively little of data on the preparedness of UK dental graduates for independent General Dental Practice. Two recent studies have indicated that graduates appear well prepared, but although quantifying the level of preparedness, they provide limited understanding of the underlying factors contributing to preparedness.

This study aims to more deeply understand the contributing factors leading to assertions of graduate preparedness using focus groups of final year dental students, and semistructured interviews of senior faculty members.

\section{Materials and Methods.}

Three UK dental schools were visited in order to conduct both study elements. Focus groups and semi-structured interviews were audio recorded and fully transcribed. Thematic analysis of the transcripts resulted in the production of a thematic matrix. Results.

The major categories of the thematic matrix were classified as extrinsic; including the role of educators and features of the course, and intrinsic; relating to fear of the unknown, the development of adult learning abilities and less easily identifiable attributes in the development of competence, which became known as 'bricks and mortar'. 


\section{Discussion.}

Students felt that the most important factor affecting their preparation was clinical exposure. Outreach placements were felt to be particularly useful, the simulation of general dental practice being highly valued by final year students.

The interaction with educators was also felt to be a key influence on preparedness, with the involvement of general practitioners in dental school teaching felt to be helpful, perhaps giving students an extended exposure to general practice.

\section{Conclusion.}

It is hoped that the rich data derived from this study may allow an invaluable insight into factors contributing to preparedness of new dental graduates, which may then be considered in the light of any proposed changes in the curricula or syllabi.

\section{INTRODUCTION.}

The preparation of dental graduates is essential to quality assure safe and effective dental practitioners from the point of first registration. The General Dental Council (GDC) view the aim of the undergraduate course is to produce a 'safe beginner' which they define as 'a rounded professional who, in addition to being a competent clinician....will have the range of professional skills required to begin working as part of a dental team and be well prepared for independent practice. They will be able to assess their own capabilities and limitations, act within these boundaries and will know when to request support and advice' (1). 
During the time of this study, the GDC's programme of school visits led to their first annual review of education (2). They found that students were competent before commencing supervised clinical treatments and appropriately supervised when providing patient care, but found challenges with monitoring and recording students' assessments and providing evidence of students' clinical experience.

A later GDC report (3) found that students understood the importance of professionalism and personal reflection, but schools were still finding the tracking of assessment in the workplace and outreach, and blue-printing of exams and other assessments against the learning outcomes challenging.

In the relatively limited number of historical studies investigating dental graduates' preparedness, there appeared to be a general perception by Dental Foundation Training Educational Supervisors (ESs) that undergraduate training has been 'diluted' and that new graduates entering their practices as FDs are not as capable practically as they once were $(4,5,6)$.

Although new graduates appeared satisfied with their undergraduate experience, certain areas were felt to be poorly covered by the course, in particular endodontics (7) and surgical extractions (8), which correlates with feelings of low confidence in these areas (9-13). Non clinical areas of low confidence included practice management, health and safety and staff management $(12,13)$.

Concerns have been highlighted in a recent study of final year students in one dental school which found $80 \%$ of them felt unprepared for the clinical work presented (14). A comparison of school restorative requirements which allowed students' entry to finals 
(15) showed wide variations across the UK, and concluded that it was unlikely that students are competent in bridgework and multi-rooted endodontics upon qualification, due to the low numbers 'required' by their undergraduate schools.

The preparedness of new dental graduates in England and Wales across the whole undergraduate curriculum has been examined at 6 and 40 weeks of Dental Foundation Training (DFT) $(16,17)$.

While giving a long overdue quantitative benchmark of a dental graduate's preparedness for GDP across the full breadth of the curriculum, the Graduate Assessment of Preparedness for Practice (GAPP) questionnaire used in these studies is unable to capture complex experiences and feelings that cannot be meaningfully expressed by numbers, and which contribute to a holistic picture of students' experiences $(18,19)$.

Qualitative research is particularly useful when attempting to elucidate new and unexpected causation to a particular phenomenon (20). Due to the relative paucity of qualitative research addressing this phenomenon, it follows that much of this knowledge as yet remains to be meaningfully articulated.

Focus groups and interviews have previously been used to sample opinions of FDs and ESs regarding their experience of DFT (21). This highlighted concern of ESs that core practice and instruction were being provided, which in the past would have been delivered in dental school.

A more recently published qualitative study looking at new graduates' preparedness has elected to incorporate views gleaned from semi-structured interviews of a wider group of stakeholders in a single locality (22). In contrast, this study was keenly focussed on 
understanding the elements contributing to the students' concept of their level of preparedness for independent GDP, rather than others' expectations. The inclusion of their educators' views was planned in order to potentially glean explanatory or moderating information in order to better contextualise students' views. A previous study of dental course directors found that $85 \%$ were confident that they were able to make accurate decisions about students' readiness to practise after graduation (23).

Thematic analysis is a method for identifying, analysing, and reporting patterns within qualitative data (24) and the culmination of the process is the development of a thematic matrix, which describes the emergent factors contributing to final year students' preparedness. This provides an invaluable adjunct to the quantitative data derived from the GAPP questionnaire at the beginning of DFT (16), allowing more insightful conclusions to be drawn about the underlying drivers contributing to dental students' assertions of their preparedness for independent GDP.

\section{MATERIALS AND METHODS.}

\section{Researcher Involvement.}

The first author carried out all elements of the study; moderating the focus groups, conducting the interviews and data processing. Although data collection was conducted alone, throughout the thematic analysis all authors participated in development of codes, themes and categories contributing to the final thematic matrix.

The first author is a general dental practitioner and experienced Foundation Training Programme Director, while the contributing authors comprised a dental school dean, 
senior lecturer in research methodology and senior lecturer in education. These contributing authors regularly reviewed the thematic analysis, in order to moderate the potential bias inherent in a single researcher's epistemology.

\section{Recruitment to the study.}

In consideration of the research aim, purposive sampling required us to contact final year dental students. Consequently, letters were sent to the heads of all 13 UK dental schools, giving a detailed overview of the research and requesting participation. Participating schools were asked to identify a senior member of faculty responsible for the undergraduate curriculum, (the UEL) who would participate in the semi-structured interview.

The UEL was asked to set aside an hour for their interview a suitable private room for the focus groups, to encourage open dialogue between the students.

\section{Focus Groups.}

Participating schools were provided with explanatory information to facilitate the recruitment of student volunteers. There was no control over the selection of participants by the UEL.

Focus groups were audio recorded using two MP4 recording devices, and their content transcribed. Time-stamped researcher notes were subsequently added to the transcription to facilitate contextualisation of comments made. 
The focus group commenced with an introduction which assured participant confidentiality, after which discussions were instigated with the opening question;

'How do you feel your undergraduate training has prepared you for a career as an independent general dental practitioner?'

In the event of discussions going off topic, or discussion drying up, the following supplementary questions were used:

'How confident do you feel as a practitioner? Were there any aspects of training that facilitated / hindered this?'

'How do you envisage dental foundation training contributing to your development?'

\section{Semi-structured Interviews.}

Semi-structured interviews were also audio recorded and researcher notes made where appropriate. The question schedule comprised the following question areas;

A description of the undergraduate curriculum,

Their involvement in the curriculum and its evolution to date,

Potential developments they think will be required,

How they would describe a graduate from their school,

The interface of the school with Dental Foundation Training, and

A description of the Faculty and their training. 
Due to the conversational nature of the interview, there was considerable flexibility in their coverage and emergent themes considered germane to the project were explored as they arose.

\section{Data Processing.}

All transcripts were initially reviewed against the audio record and amended as required to ensure faithful and accurate representation of discussions.

During verification, focus group participants were allocated anonymous codes to track individuals' responses throughout the transcript. Researcher comments within the transcripts were highlighted and researcher notes were added to the master transcripts, but neither formed part of the initial data analysis.

The transcribed data from both the focus groups and semi-structured interviews was analysed as a complete data set, using Thematic Analysis.

The analytic process was an iterative and reflexive data analysis spiral, where processes were interrelated and often simultaneous.

Although the coding and development of the thematic analysis was carried out by the first author, regular review of coding and the development of categories and themes was carried out by all authors.

During the initial review of transcripts and annotation with researcher notes, data familiarisation and memo writing began. 
Memos were generated at every stage of the analysis, and recorded alongside the transcript, in order to preserve the independence and interdependence of the data transcript and the researchers' observations.

Repeated review of the coded data, transcript and memos led to further memo generation, and to categorisation and the development of emergent themes based on more abstract concepts rather than a simple content analysis.

Transcripts were initially coded using a statement coding approach, and rather than risk decontextualizing words or sentences by anatomising the data too far, it was often categorised multiply into different codes. This was completed manually, helping to assure the preservation meaning and context.

In order to maintain the accuracy of data allocation to particular codes, unless data could fit seamlessly into a pre-existing code a new code was generated, initially resulting in an large number of them. As existing themes began to recur, the number of new codes diminished. Some elements of the transcript were un-coded, if they were felt to be unhelpful, such as conversation filler or repetition.

During this process, it became clear that there were broader themes inherent in the contextual codes and categorisation became an intuitive next step to take.

During coding, 'higher level' themes began to emerge, which cross-linked the contextual codes or subsumed several of them into larger themes. These themes became the major categories, viewed in the context of the central theme of graduates' preparedness for practice. 
Within each major category, underpinning categories were generated retrospectively to allow appropriate data representation. While some of the original contextual codes did appear as underpinning categories if they remained representative, others were novel constructs based on deeper immersion in the data.

Data analysis was consequently a combination of a manifest (25) and latent (26) content analysis, based upon how the words were actually used (27).

The duplicative approach to contextual coding facilitated the cross-linking of themes facilitating matrix development. Themes which arose but were not related to the central theme were not included in the generation of the thematic matrix.

\section{RESULTS.}

Recruitment to the study.

Only eight responses were received from schools after the initial contact. Three of these declined participation outright, two of which cited an overlap with their own research. Despite follow-up emails, there were no further schools recruited.

Three schools participated; one being a graduate entry school (B), while the other two were co-housed with dental hospitals, both accepting graduate and undergraduate entry students.

Two of the schools had scheduled the semi-structured interviews first $(A, C)$, and focus group immediately afterwards, the opposite being the case for School B.

\section{Participant Descriptive Data.}


The descriptive data for the focus group participants are displayed in Table 1.

TABLE 1 TO BE ENTERED HERE

School B was a graduate-entry (GE) school, and explained the older cohort of participants. There were no GE students in either of the other groups, although there were GE students within the schools. The gender constitution of the groups was heavily weighted towards female participants.

Both Schools A and C had UELs who had spent most of their careers working within the dental school environment as educators, while the UEL from the GE school (B) had a significant and broad base of primary care employment experience. No UEL had completed VT or DFT.

\section{The Thematic Matrix.}

The thematic matrix is displayed as Figure 1. It was developed throughout the data analysis using an iterative cycle of repeatedly checking the adequacy of the major and underpinning themes.

Figure 1: The Thematic Matrix. 


Each categories of the thematic matrix is a different size which reflects the degree of data derived from the qualitative analysis. This is not an attempt at quantitising the categories into a hierarchy of importance, but rather a subjective illustration to the reader of the volume data obtained, interpreted and presented.

\section{Intrinsic Factors.}

This term encompassed the student-related factors influencing preparedness.

'Bricks and Mortar' was introduced to represent the researchers' thoughts on the data which appeared to indicate the participants' identification of the difference between learning about dentistry (discrete bricks of knowledge) and becoming a dentist (the mortar that cements the bricks of knowledge together).

'Fear of the Unknown' reflects the observed oscillation between the students asserting their confidence, and statements made elsewhere belying their assertions, resulting in apparent uncertainty of what was actually required for them to be prepared.

Several areas of the data pointed to the students lying at varying loci on the path to becoming into an adult learner; and essential requirement for professional independence.

\section{Extrinsic Factors.}

This major category encompassed all factors perceived to affect students' preparedness which they did not directly control. Although all extrinsic factors were effectively all 'course related', we felt the frequency of Educators arising in the data necessitated a 
category of its own. We understand that certain areas of discussion may only reflect issues from a single school.

\section{DISCUSSION.}

\section{Credibility and Dependability.}

This study relied on the researcher's ability to capture the reality of information at a given point in time, in the context in which it was derived. Consequently data can be misinterpreted, described with bias, or considered normative when it may be an extreme view. As a result, this study does not seek to extrapolate these results as representative of the wider population.

The credibility of qualitative studies is enhanced by data source triangulation (28). The emergence of substantially similar viewpoints in several different groups tending to support the studies credibility (29). Its dependability is enhanced by the same researcher conducting all focus groups and interviews and coded and analysed all data.

\section{Data Saturation.}

Since there have been significant differences in reported preparedness of new graduates between undergraduate schools $(16,17)$ all UK dental schools were initially contacted at the outset, with 3 schools eventually participating. Although many common themes emerged from the different schools in this study, each group introduced unique insights into factors affecting their preparedness. Under these circumstances there was a potential lack of data saturation $(30,31)$, in which case the thematic matrix may be incomplete. 


\section{The Thematic Matrix.}

In the discussion of the themes below, direct quotes from participants were carefully chosen to be illustrative of the postulates presented.

\section{Intrinsic Factors.}

Bricks and Mortar.

In SSIA, the UEL described how the initial change to dentistry becoming a degree course led to students knowing a lot about dentistry, but not necessarily making good dentists. He felt recent changes were redressing this overly academic focus, and they were now 'training to be dentists.'

The UEL in SSIB also alluded the importance of developing the mortar;

'We're not training them to be robots; we're training them to think.'

Altruism.

A fundamental tenet of healthcare professionals is to put others' interests before their own. In two of the groups there were clear demonstrations of this; both in terms of their patients and peers. This extended to doing the right thing even when it directly conflicted with their own interests, particularly in regard to achieving requirements. In FGB (Focus Group - School B) and C the students described examples of swapping patients to assure others' requirements were completed. 
Patients' treatment plans were changed by different staff, and while frustrating to the students, they were more aggrieved by the inconvenience to their patients.

It may be that the essential elements of 'mortar' may transcend certain deficiencies in knowledge or clinical experience when out in practice. Skills and knowledge develop with experience, but one may not be able to correct an inapt sense of professionalism.

There was also mention in all FGs that they wanted to contribute to course improvements for subsequent years, despite some cynicism as to the degree of influence staff-student liaison committees had in bringing about change.

\section{Knowing When to Seek Help.}

The ability to recognise the limit of one's ability is a significant milestone for a novice. The UELs in both SSIA (Semi-structured interview - school A) and C both felt confident they were producing safe beginners who were self-aware regarding their strengths and weaknesses. Ali et al. (22) also found this to be the a common theme in their semistructured interviews of multiple stakeholders. In this study, the students in FGC also appeared confident that they were sufficiently self-aware;

'We all know we haven't got a vast amount of experience... but I feel comfortable that I at least know what I am doing and I know when to ask for help.' 
This may explain why students in this group were so frustrated by premature intervention on clinic. The converse is also possible; perhaps supervisors felt that some students had not developed sufficient self-awareness, resulting in need to intervene.

Some students appeared uncertain about the level of support they will receive in DFT, and so while they felt the level of 'help' was stifling as a student, there appeared to be an unspoken gratitude about its presence.

\section{Dealing with Ambiguity.}

Throughout the transcripts there were several references to students having to deal with clinical situations to which there was no definitive answer, or dealing with differing faculty opinions.

In SSIA, the UEL extolled the value of being exposed to different ways of approaching a problem in order to develop as a clinician. While some students agreed, others appeared unable to rationalise the ambiguity, and generate a definitive treatment plan;

'Sometimes you have so many different opinions you are not sure what the right thing to write down is. I know every way works but... which is the right opinion...for exam reasons?'

\section{Decision Making.}

This was a strong theme in the FGs and is essential mortar in the mastery wall: Patients present unique challenges which require a complex assimilation of previous experiences. Concerns about their preparation in this regard were expressed early in FGA; 
'Skills wise I feel confident enough to go out...but with decision making it feels a bit like you don't ever really make any of your own decisions...so I feel happy I could go and do a bridge, but I'm not so sure why someone wouldn't be suitable to have a bridge.'

They appear to be happy with the 'bricks', but perceived that premature interventions by educators to be a major hindrance to developing these skills;

'Decision making...is really important and probably the only thing where we might be slightly failed on in our education here'.

'The transition between here and practice isn't about how well you do a composite filling or pack amalgam...the difference is...decision making ...they don't address that.'

This was compounded by insufficient explanations of why educators made particular decisions;

'At no point did anyone actually explain why...You're left none the wiser.'

One student described their experience of outreach being better. After discussing the treatment rationale with the tutor they were allowed to proceed. It may be that the primary care practitioners had a different approach to developing these skills than university faculty. 
Development of these essential skills comes with experience, and in SSIB, the UEL identified that some students who would not graduate were identified later in the course, due to their inability to;

'Problem solve... That bit we do automatically.'

\section{Fear of the Unknown.}

Leaving the Cocoon.

In FGA the students used similies to describe their feelings of transition to independence. The last minute information delivered in preparation for the NR process led to considerable anxiety that the end was approaching rapidly;

'Suddenly it felt like we were like being literally pushed out of the bubble.'

Earlier in the FG the dental school 'bubble' was referred to as a cocoon, that had protected them from some of the perceived realities of independent GDP, presumably sensed during their limited Outreach placements;

'We've just been cocooned in this little dental school; we don't really have any idea of ...practice... that's something that we're not taught here.' 
Transition to practice did not feature in FGB, possibly reinforcing the value of their primary care-based course in gradually assimilating to the GDP environment.

\section{Have I Done Enough?}

The category title is deliberately ambiguous, serving to describe two prevalent themes.

The first relates to the need for requirements, which some students felt was ill defined and ambiguous.

The second theme was this intrinsic uncertainty in having gained sufficient clinical experience to be prepared for independent practice. Some students were concerned because they hadn't completed particular treatments at all. Bridges and tooth wear were mentioned in FGC and an example from FGA was;

'Loads of people...haven't done a post crown.'

In contrast, possibly due to their greater primary care experience, students in FGB made no mention of inexperience of any type of treatment.

In FGC, students debated how many procedures were sufficient to be prepared, confounded by a lack of suitable patients and limited clinical time. Their system of competencies appeared to have a detrimental effect on confidence; 
'You would feel more confident if you had done four or five molar endos...you only really need to do one molar endo and pass the competency on it to get through to finals...You could just have had a lucky day.'

Due to the questionable suitability of requirements, the UELs in SSIs A and B described monitoring longitudinal student progression within each competency, which could be provided to students and their ESs to facilitate their transition to DFT. In SSIC a portfolio of student data compared to cohort averages were similarly available.

\section{The Adult Learner.}

\section{Educate Me.}

The importance of self-directed learning in dentistry is paramount for maintaining competence. The varying stages of evolution to an independent adult learner appeared in the FGs, and appeared to be more developed in FGB, possibly as a result of their previous academic experience, one student remarking;

'We're so far beyond sitting in a classroom being told what to do'

Despite the incorporation of reflective practice into the portfolio in School C, the UEL expressed concerns about their undergraduates and the benefit of having graduate students alongside them; 
'We have huge problems with students coming straight from school and their ability to...be independent learners... What we find the graduate entrant into the course does is that they bring with them a maturity that spreads within the group.'

In FGA there was criticism that information perceived to be essential for their preparation was only picked up 'in conversations' and even more perturbed that these conversations had been conducted in outreach. The apparent need for overt signposting of learning and concern over its non-institutional delivery was another indication of the learners' relative immaturity.

An example of students in FGA convening study sessions outside university to prepare for National Recruitment appeared to be a good example of them realising the importance of self-directed learning, but the criticism of the school not having supplied this information belied their learner immaturity;

'The most useful thing for me making the transition from university to work...has gone on outside university.'

In contrast there was little criticism of educational opportunity afforded to students in FGB. Perhaps their more matured learning skills rendering them more capable of identifying and seizing educational opportunities.

Fragility of New Knowledge. 
Some students in FGA and C expressed concern around maintaining their newly acquired clinical skills over the long summer period;

'I haven't done anything since Easter, which is now slightly concerning me...l am not going to remember how to pick up a handpiece!'

'I don't feel my skills are that drilled into me yet, that I can just go back to it having such a long break.'

They felt they would have been prepared had they gone straight into practice, exacerbated by their feeling of insufficient clinical exposure. This may also explain the absence of this issue arising in FGB; their more extensive clinical exposure leading to their clinical skills feeling more embedded.

In SSIA the UEL described identifying a similar issue. Concerned about the gap between learning advanced restorative techniques and a suitable patient attending, he was considering implementing interim refresher sessions on patient simulators, also potentially ameliorating the pressure to meet requirements.

The fragility of new knowledge was apparently not only subject to temporal interference. One group suggested rescheduling final examinations to earlier in the course would remove the distraction of finals from this period of honing clinical abilities. It was as though students felt like the focus on examinations was going to displace their clinical knowledge. 
Driven by Assessment.

In FGB, one student felt the need to have more assessments in order to drive their learning which conflicted with the self-motivated learner one expects a young professional to be;

'If someone puts a test in front of me, then I know I have to work.'

In FGA, the impending National Recruitment process had apparently driven a 'last minute' series of lectures on important topics. This not only exposed a potential lacuna in their education, but possibly made these students feel unprepared; wondering what other areas the dental school had missed that they didn't know about.

In SSIC, the UEL explained that many of the curricular learning outcomes were assessed longitudinally, which may have contributed to the student's view that certain areas had not been taught thoroughly enough, having not been formally signposted as assessments. The UEL in SSIA also felt this was preferable to summative assessments;

'I don't believe in a finals examination, I think it is a strange idea to have all this data and then it come down to a few hours of testing... Whether we can ever move away from that I'm not sure.' 
This may allude to the need for the university to maintain summative requirements within the degree programme, in order to help demonstrate academic rigour and quality-assure the education provided.

Unfortunately a focus on the formal curriculum may lead to a devaluing of the intangible benefits of both the hidden curriculum (institutional practices and culture) and informal curriculum (ad hoc interactions among teachers and students) particularly in such a vocational subject as dentistry. We have seen above how crucial both of these elements of the dental educational environment are crucial to the development of the students as dental professionals.

\section{Extrinsic Factors.}

Course Factors.

\section{Transition to DFT.}

Outreach was considered to be an invaluable experience in students gaining an understanding of GDP. Possibly linked to their CDS outreach programme, students in FGC were uncertain of the expectations;

'We will probably see as many patients in our first day as we have seen in our whole year!' Their UEL appeared aware of the resulting lack of preparation for GDP, feeling they would need 'a lot of support' in the early days;

'I'm not convinced that it's something we can deliver particularly well.' 
This contrasted starkly to the confidence expressed by the UEL in SSIB regarding the transition;

'Our students do primary care dentistry in a primary care setting, so Foundation Training doesn't surprise them.'

This was reinforced by the school having received feedback that ESs wanted their graduates because 'they hit the ground running'. The most recent report of preparedness for independent GDP confirms this, with large discrepancies in reported preparedness of new graduates between 4- and 5-year courses (16), which were significantly reduced by the end of DFT (17).

Liaison between DFT and dental schools was considered by UELs and students to be beneficial. In SSIA the UEL expressed frustration at the wealth of data offered to DFT on student performance which had been met with disinterest, while in School C this had been gratefully accepted.

The transition to DFT includes students successfully negotiating the National Recruitment process. Consequently, all schools had urgently incorporated learning schemes to better prepare their students, often with the close assistance of DFT schemes.

School B had provided students with their own programme on preparation for DFT and National Recruitment from fourth year, facilitated by many of their clinicians being ESs previously. This had apparently been extremely successful, the UEL claiming their 
students to have come top in the National Recruitment ranking process in the three years it had been running.

School $\mathrm{C}$ had also jointly implemented a system to provide supplementary training on phantom heads during the long summer break after finals, addressing concerns by the school and students. This still appeared to be a significant concern to students in FGA.

\section{Heterogeneous Experience.}

In all groups there were references reflecting the unique experience for others on their course or at other universities. Some students referred to having discussions with peers at other schools, while it may be that others' based their assertions on assumptions, and consequently these comments were cautiously interpreted.

In FGB despite an overall positivity towards their course there were some issues raised, one being exacting requirements;

'Our requirements are way beyond that of any other dental school...they have met their requirements and done less work... We haven't met our requirements but still have more to do!'

Despite their perception of being on a 'better' course, FGB participants debated their heterogeneous experiences within the school, perhaps magnified by their geographical isolation due to decentralised sites and different cohort of educators. 
Although local patient demographics may contribute to subtly different treatment profiles, areas of particular interest to their supervisors was considered to influence their experiences, especially with more advanced treatment modalities, for example;

'I know that some people...have done loads of minor oral surgery...we tend to refer most of them out.'

The differences were also apparently quite stark between School B's placements in secondary care. Some felt they were 'quite good' while others described their orthodontics and oral surgery experience as sometimes compromised as a result of an institution's balance between undergraduate training and other commitments such as service provision and postgraduate training;

'We... can't get a look in...if there is anything the consultant thinks that a student could do it's the DF2s that it gets given to, not the dental students.'

'Even though they're told to cut the lists because students are coming in and you have to teach them, they've then got a pressure from above them to see $x$ number of patients so sometimes it doesn't work.'

These tensions appear to be present, despite having been identified as a concern in undergraduate training nearly a decade before by the GDC (32). 
In FGC, students felt 'quite fortunate' to have elements of teaching that others apparently didn't; specifically sedation, oral surgery and implants.

\section{Requirements.}

One of the ubiquitous topics across all FGs were discussions involving the need to complete certain treatments to a satisfactory standard to enter finals. We refer to them as requirements, although the schools had their own nomenclature. Youngson et al. found that across the UK and Ireland, these requirements varied considerably both in their nature and quantum, with some only using competence assessments, while others used a combination of numerical and competence assessments (15).

Certain more advanced treatments were mentioned in all FGs as being areas where the students felt they needed more experience. This was within the contexts of needing specific requirements to enter finals and also from a reflective standpoint on their preparation for independent practice.

The treatments in which students felt they required more experience was encapsulated by a student in FGC;

'There are still a lot of aspects that I don't feel $100 \%$ confident at...complex restorative stuff like bridges, whereas fillings or perio I feel fairly confident to do by myself... we have done perio and cons since the beginning of third year, whereas the crowns and bridges, we have done from fifth year, so we have had less time to do it.' 
These topics have recently been highlighted as areas where Foundation Dentists and their supervisors felt less prepared at the beginning of their Foundation Year (16).

This concern is difficult to resolve for dental schools: More advanced treatments require significantly greater skills and so tend to be taught later in the course as clinical dexterity increases, but there is a correspondingly reduced amount of time in which to gain experience of them. This led to descriptions of acute pressure to complete requirements. The converse is true for the less complex treatments such as fillings or periodontal care, and may be more likely to have become embedded, compared to those recently acquired (and more complex) skills.

An additional confounding factor in becoming prepared in advanced skills was the availability of suitable patients, for students in schools A and C. Many patients were sourced from emergency clinics, but often failed to attend for routine treatment appointments, while others did not meet the exacting criteria required to be assessed as a 'requirement'. This was compounded by the need to stabilise the patient's disease before progressing to more complex treatments in an increasingly short period of time. In contrast, patients in School B accompanied students on their journey through the course from the beginning, engendering a long-term relationship, with their need for complex treatment arising at an appropriate time in their treating student's experience. An unexpected complication arising from the lack of suitable patients became apparent in FGA; 
'I think there's a shortage of patients for us to treat in a wide range of things, so that we are getting more and more difficult cases.'

The student seeing the irony of the treatment being too complex for a dentist in GDP warranting specialist referral to dental hospital, only for it to have been allocated to her;

'I don't mind doing it...it's re-root canal so it's a specialist treatment that we're providing with a general dentist education!'

This was commented upon by the UEL in SSIB, concerned that new graduates from other schools didn't recognise their undergraduate experiences as being adequate preparation for primary care dentistry, consequently reducing their 'useful' clinical experience; 'In other dental hospitals... the patients are too advanced for them... That's what they have seen as dentistry, how much of it they've done is debatable, but that's not what dentistry is!'

If clinical supervisors were alert to these issues around complexity, they may have been more likely to intervene earlier rather than later, which may account for the perception of students that this was premature in FGA and C.

Despite clear anxieties relating to requirements, the students' insistence in treating the patient holistically despite the significant conflict with their own needs was testament to their professionalism. For some it apparently distorted their attitude towards patients; 
'The competencies encourage you to get tunnel vision...fifth years up to finals, it is literally "have you got a molar endo, have you got a crown?" Not "have you got a patient who needs a molar endo?"...they turn into treatments.'

Once the minimum requirements had been achieved, students felt a conflict between seeking increased experience which they felt they needed, and not wanting to risk getting an unsatisfactory grade. This was particularly apparent in FGC, where a competency system, meant it was possible to enter finals having done 'one of everything' competently. The system leading some to strive for mediocrity and anonymity rather than excellence;

'Once we've got our requirements...we'll just stay under the radar, and try not to do anything.'

'I think that is such an awful mentality to give students.'

Although this allowed entry into finals, students felt conflicted knowing it was also detrimental to their preparedness;

'You would feel more confident if you had done four or five.'

In SSIC, the UEL described the competency-based system having been designed to address the 'numbers vs competence' debate; 
'However much experience an individual student might need can't be determined on analysis of figures, it's...how they perform...If a quota was ever set it would probably have to be so low... it wouldn't give you any confidence in what you were producing.'

In FGB there was little apparent concern over gaining sufficient breadth of experience or in the tariff of treatment difficulty. The UEL felt that despite the target requirements being 'high compared to normal schools', students easily exceeded them.

Using the completion of a specified number of clinical procedures as a proxy for competence has been widely criticised (23), with dental students identifying 'requirement-chasing' as a major source of anxiety, in addition to concern about the potential ethical implications on holistic patient care $(32,33)$. Educators have expressed concern that students may put their own needs ahead of the patients as a result (34). Those working without requirements having been shown to be less stressed and equally as productive (35-40). Holmes et al. suggest that students may even be more productive in the absence of requirements (41).

Preclinical.

The traditional model of dental school education involved studying clinical sciences in the first portion of the course, followed by the clinical elements as described by the UEL in SSIA; 
'They start on clinics from second year...but predominantly the first three years are about getting the degree...the last two years are...clinical training.'

He went on to highlight the use of PBL within this period to develop and assess the nonclinical competencies of management, communication and teamwork. Nevertheless, the preclinical courses were roundly criticised by the students in FGA and C.

As a 4-year GE course, students in FGB had no experience of this course structure, although were aware and sympathetic to the plight of others' belated patient contact.

As described in Outreach and Decision Making, early exposure to patients and the responsibility for all elements of their treatment from the start of the course was felt to be particularly helpful in preparing students for GDP.

The medical orientation and perceived irrelevance of some preclinical topics led to frustration, compounded by their consequent lack of clinical exposure. One student reflecting on the choice of course;

'Oh my God what have I done?...It wasn't until third year that I even did my first injection!'

Later in FGA it transpired that the length of the course was not the central issue. They were more frustrated that the balance of the course failed to meet their perceived needs to be prepared for practice; they felt many 'irrelevant' preclinical modules could have been replaced with invaluable clinical exposure.

Even when dental topics were addressed in the preclinical course, the lack of simultaneous patient contact meant the theory was taught devoid of vocational context. 
The reason that one FGB student chose that particular school illustrated their perception of the 'traditional school' approach;

'I already have a degree and I don't really want to sit in a lecture theatre for a couple of years before you get your hands on a patient.'

\section{Outreach.}

The term outreach was used to encompass clinical experiences gained by the students outside the dental school or its equivalent. School B had the vast majority of its course based in primary care, which includes the 'base' where students are taught as well as outreach centres.

While most schools have relatively limited outreach programmes, as described in both SSIs A and C, School B spent the last 10 months of their course in the GDP environment. To supplement the limited outreach experience, most schools have multidisciplinary clinics in final year, in contrast to the speciality clinics in lower years. Unfortunately many elements of GDP including staffing, patient type, and exposure to the NHS system and practice management could not hope to be effectively simulated in the dental schools. In SSIC the UEL described outreach taking place in community dental service (CDS) clinics. Although this experience may include elements of general practice, such as patient charging and computer software, CDS is different, often catering for a limited scope of patients with additional needs, not effectively catered for in GDS.

In FGB, the first topic raised by students related to their primary care experience; 
'We do get a lot of exposure in general practice with the way that the course is structured; we go straight out into a general practice.'

This was clearly perceived to be advantageous;

'Compared to a lot of other students that I was talking to...they were really surprised at how much we had done compared to them... we get exposed to a lot more variety than them as well.'

In SSIA, the UEL noted that their clinical experience was not as integrated as he would like, resulting in 'state dependant learning' where students only focussed on the clinic speciality rather than whole patient care, in contrast to FGB;

'We don't see patients on a specific clinic... we formulate treatment plans all the way through from the beginning.'

This may have significantly enhanced their ability to deal with ambiguity and make decisions, and also potentially benefited them in developing non-clinical competencies by working with other dental care professionals.

The primary care-based course was summarised favourably by one of the group; 
'You have been working in primary practice since first year, and you have a lot of exposure to treating lots of patients... We are doing a lot of primary clinical work compared to other universities.'

Primary care work may incorporate both experience of the primary care practice environment and also the types of treatments that dentists are exposed to.

In FGC, students described outreach not starting until fourth year, leading to their concerns about exposure to 'the business side' of GDP at a late stage. The value of primary care practitioners working as clinical tutors was considered to be an important resource in this regard.

In FGA the outreach programme led to a new found efficiency;

'You just feel like you're so much quicker, you're so much more confident doing stuff, you don't have someone breathing over your neck the whole time...You actually come out of it feeling so good.'

This made the return to the much lamented restrictions of dental school all the more frustrating. Exposure to the general practice environment had apparently increased confidence and freed students from the stifling effect of supervisory faculty, which had previously made them feel unprepared; 
'They're still making us check on every single stage...I've been doing it since second year and you're still making me feel like I don't know what I'm doing!'

\section{Educators.}

\section{Specialist or Generalist?}

In School B, the clinical elements were largely delivered in a primary care setting, and in SSIB, the UEL noted;

'Most of the senior clinical teachers have had most of their career based in primary care. We feel it is a much more realistic environment for the students.'

This differed to the other schools, whose focus groups raised concerns around changing plans between faculty with different backgrounds and the timing of interventions, particularly in outreach.

The students in FGB agreed that this prepared them well for a role in primary care, but they perceived other consequences regarding their preparation in other areas;

'We get a lot of clinical experience, the down side is that there are no specialists teaching us...if you wanted to specialise after this then you are closed off a little bit.'

The students in FGA appeared concerned about the apparent mismatch of educators' qualifications and their teaching role; 
'His speciality is oral surgery, but he actually doesn't have any qualifications at all...he has only got a BDS...So for us to be getting advice and being taught by him...is strange isn't it?'

The perception was that students were not fully prepared for independence having been taught to 'GDP-level', and there was a need to have a reserve of higher level expertise available to them to call upon.

This was apparently being addressed with the UEL in SSIB indicating that more consultants were being appointed to 'reinforce the teaching.'

One member of FGB felt the lack of specialists was less of an issue, feeling they were better prepared by 'generalists' for their future in GDP. Ideally the blend of specialist higher level teaching and support and GDP experience felt right to them, one student describing this as 'multidimensional'.

Inefficiencies of dental school clinics were highlighted, in particular the perception of the institutionalised staff having no desire to do more than necessary, in stark contrast to the student's hunger for experience, and to their perceived detriment.

\section{No Sense of Urgency.}

There were two passages of dialogue in FGA relating to students attempting to use their clinical time more effectively. This was in the context of the group bemoaning their general lack of clinical experience, and that increased efficiency and initiative were felt by students to be important areas of preparation for independent practice. 
In the two 'traditional' schools, staffing arrangements were recognised as not accurately simulating GDP, and this was also perceived as an impediment to their development. The differences starkly highlighted on their return from Outreach placements where they had the benefit of administrative and 1:1 nursing support. One student described booking four simple review patients in on a dental school clinic using their new-found efficiency from Outreach, only to be told it;

'Wasn't suitable due to patient turnover.'

It made this student feel that the 'staff just wanted to go home early.'

Another student was particularly animated in describing dental school staffing;

'How inefficient everything is...I feel like with all of the staff...there's no sense of urgency, even the tutors... This is so inefficient, and this is my training!...I'm paying to be trained at this university... it just really upsets me, because I feel like I am here to learn, and you're just a barrier to my learning!'

In SSIC, the UEL described a drive to reduce the amount of primary care clinical teachers doing a small number of sessions, by increasing the amount covered by those; 
'Genuinely interested in the role and providing support and teaching for the students rather than coming because it is relatively easy day away from practice.'

It appears that both students and senior faculty have identified this as an area which could lead to significant improvements in the students' clinical experience.

\section{Changing Plans.}

Several anecdotes in the FGs described clinical supervisors having conflicting opinions about a particular patient treatment plan. While for some students, dealing with ambiguity was difficult, others felt it enhanced their ability to deal with novel situations. Where present, concerns focussed on the lack of accompanying explanation, depriving students of exposure to expert thought processes;

'(We) know that dentistry isn't black and white... and there's always going to be different ways that different practitioners work... (but) they change it without telling us why. We haven't learned from that!'

There appeared to be particular anxiety associated with plans changed as a result of differences of opinion between part-time clinical supervisors who worked in general practice and dental school faculty. This caused the students to question how well their dental school education prepared them for GDP, if dental school faculty were being contradicted by general practitioners. 
Holding Me Back.

The absence of being exposed to the thought processes of experienced clinicians was contributed to the students feeling underprepared;

'A hindrance... you're not learning from them why they do things the way they do.'

The UEL in SSIA described concerns he had regarding the 'defensive feedback' given by some clinical supervisors, which he felt failed to address the student's development needs for fear of demotivating them, while reinforcing their suboptimal performance.

Some secondary care staff were felt by some in FGB to have hampered their progress, while others had excellent experiences. They felt that tensions between service provision, postgraduate training pathways and their undergraduate educational experience was detrimental. The educators described as;

'Just so busy that they haven't got the time to be able to talk you through everything or let you have a go or anything.'

Intervention.

During clinical training, the importance clinical supervision in order to ensure patients' wellbeing is recognised, and one may expect this to be proportionate to individual students' competence. 
In FGA one student described being frustrated that they considered an early intervention resulting in a lower clinical grade for 'independence', which they felt would have been better without the premature staff involvement.

In SSIA the UEL was aware that some staff were 'overzealous' in their intervention, sometimes resulting in students receiving lower grades. This was being addressed by calibrating grades against the student's overall profile, allowing the UEL to give formative feedback to particular supervisors on their assessments.

The students also felt that the point at which supervisors intervened was inconsistent; some pre-empting problems while others allowed students to progress further before they 'jump in'. Intervention caused one student to question their previous feelings of preparedness;

'Every one of us needed an intervention...it appears that we're not ready, but actually I know that we are...sometimes you get early intervention from clinical staff when you don't necessarily need it.'

It was also considered unhelpful at times; another student describing it as giving 'false confidence', having been told on an oral surgery clinic;

'It doesn't matter what happens 'cos we'll take care of do you.' 
Although well-intentioned, the all-encompassing protection provided by staff appeared to confound the students' decision making abilities regarding what tariff of difficulty was within their own competence; the student recognising that they could 'get in a mess' in the absence of supervision;

'They're trying to hold us in and rein us in...How can we deal with that on our own when we're out in practice?'

Later in the discussions, staff interventions were viewed as a potentially important source of learning provided they were accompanied by a clearly articulated rationale behind their approach.

The quality of feedback by undergraduate educators had been criticised by UELs and students in this study. Feedback, particularly on incorrect performance (disconfirming) is crucial in the transition of learners from unconscious incompetence to conscious incompetence (42). This was singled out in SSIA as a particular weakness in tutor feedback, but may be related in part to the difficulties of articulating and interpreting tacit knowledge. Dental faculty have reported feeling uncomfortable giving such feedback, and consequently avoiding doing so, both to shield the student and protect themselves and avoiding confrontation (43).

Helping me Flourish.

In FGA the first student response after being asked the introductory question was; 
'Probably quite well (prepared) in terms of support we get off staff.'

In FGC, educators were also the subject of their first comments, a positive reflection of how clinical supervisors weaned students off supervision as they gained experience throughout the course, resulting in feeling 'quite independent' by the final year.

FGA and C spent proportionally much longer discussing negativities relating to their educators, providing an interesting contrast to the primacy of these positive comments. The importance of having experienced 1:1 dental nurse support was espoused in FGB, contrasted by these students to 'other schools' that had to share nurses or assist each other. Not only was this perceived to contribute to the efficiency of the students' clinical practice but also as a source of help and advice;

'Just a lot slicker and a lot faster and obviously they know a lot as well so they can obviously impart a lot of their knowledge onto to you.'

The other advantage of this was felt to be the development of students' team-working, management and leadership skills.

\section{CONCLUSION.}

This study has provided invaluable insight into factors which appear to greatly influence dental students perceptions of their preparedness for independent GDP. 
Due to the limited number of participants, and the situational and subjective nature of this study, care must be taken in attempting to extrapolate these results to a wider population. Coupled with the quantitative assessments of new graduates' preparedness across the UK undergraduate curriculum derived using the $\operatorname{GAPP}$ questionnaire $(16,17)$, a more robust illustration of new graduates' preparedness can start to be formed.

In this study the overriding sense we gained was that students felt that the most important factor in their preparation was clinical exposure to patients. In particular treatment planning for patients with educators from general practice was felt by to be more attuned to their future work in practice. The added benefit of a general practice environment in which to receive this guidance, which we have termed 'outreach' appeared to be the most beneficial factor to them in their development.

Preclinical programmes were felt to be of much less value to the students, especially in light of their assertion that clinical time was already insufficient.

Increased clinical exposure may however provide significant challenges to the current status of undergraduate dental education in the UK, not least expense. These challenges include the quality assurance of expanded outreach environments and their educators that would be required to service an expanded programme.

Further qualitative studies are urgently needed in order to extend and verify the thematic matrix as representing the factors influencing students' preparedness in UK dental schools. We anticipate this matrix will evolve over time, as courses are further refined to meet the needs of contemporary dental graduates. 
We hope that this research is useful to those responsible for the design and delivery of both undergraduate and postgraduate dental education in the UK, and that future qualitative studies continue to inform educators as they plan developments of their educational programmes.

\section{REFERENCES.}

1 General Dental Council Preparing for Practice. Dental Team Learning Outcomes for

Registration. GDC, 2011: London

2 General Dental Council. Annual review of education 2012/13. GDC, 2013: London.

3 General Dental Council. Annual Review of Education 2013/14. GDC, 2014: London.

4 5Levine RS. Experience, skills and knowledge gained by newly qualified dentists during their first year of general practice. BDJ, 1992; 17: 97-102.

5 Allen WR Mandatory Vocational training for the General Dental Services. BDJ, 1993; 175:

188.

$6 \underline{\text { Patel J, Fox K, Grieveson B, Youngson CC. Undergraduate training as preparation for }}$ vocational training in England: a survey of vocational dental practitioners' and their trainers' views. $B D J, 2006$; suppl: 9-15.

7 Stewardson DA, Shortall AC, Lumley PJ. Endodontics and new graduates. Part 2: Undergraduate experience and course evaluation. Eur J Pros Restor Dent, 2003; 11: 15-

21. 
8 Greenwood LF, Townsend GC, Wetherell JD, Mullins GA. Self-perceived competency at graduation: a comparison of dental graduates from the Adelaide PBL curriculum and the Toronto traditional curriculum. Eur J Dent Educ, 1999; 3: 153-158.

9 Kay EJ, Blinkhorn AS. Scottish dental students' views on their undergraduate training. BDDJ, 1987; 162: 317-319.

10 Brookman DJ. Vocational trainee's views of their undergraduate endodontic training and their vocational training experience. Int Endo J, 1991; 24: 178-186.

11 Murray FJ, Blinkhorn AS, Bulman JS. An assessment of the views by recent graduates on their undergraduate course. Eur J Dent Educ, 1999; 3: 3-9.

12 Bartlett DW, Coward PY, Wilson R, Goodsman D, Darby J. Experiences and perceptions of vocational training reported by the 1999 cohort of vocational dental practitioners and their trainers in England and Wales. BDJ, 2001; 191: 265-270.

14 Gilmour ASM, Welply A, Cowpe JG, Bullock AD, Jones RJ. The undergraduate preparation of dentists: Confidence levels of final year dental students at the School of Dentistry in Cardiff. BDJ, 2016; 221:349-354.

15 Youngson CC, Molyneux LE, Fox K, Boyle EL, Preston AJ. Undergraduate requirements in restorative dentistry in the UK and Ireland. BDJ, 2007; 203 (Suppl): 9-14. 
16 Ray MS, Milston AM, Doherty PW, Crean S. How prepared are foundation dentists in England and Wales for independent general dental practice? BDJ, 2017; 223: 359-368. 17 Ray MS, Milston AM, Doherty PW, Crean S. How prepared are foundation dentists for independent general dental practice at 40 weeks of foundation training? FDJ, 2018; 9: 2633.

18 Berg B. Qualitative Research methods for the Social Sciences. (2004) Boston: Allyn and Bacon.

19 Öhman A. Qualitative Methodology for Rehabilitation Research. J Rehabil Med, 2005; 37: $273-280$.

20 McEvoy P, Richards D. A critical realist rationale for using a combination of quantitative and qualitative methods. J Res Nurs, 2006; 11(1): 66-78.

21 Clow R, Mehra S. Evaluation of vocational training of dentists in three different regions. $B D J, 2006 ; 201: 774-778$.

22 Ali K, Tredwin C, Kay EJ, Slade A, Pooler J. Preparedness of dental graduates for foundation training: a qualitative study. BDJ, 2017; 217(3): 145-149.

23 Albino JEN, Young SK, Neumann LM, Kramer GA, Andrieu SC, Henson L, Horn B, Hendricson WD. Assessing Dental Students' Competence: Best Practice Recommendations in the Performance Assessment Literature and Investigation of Current Practices in Predoctoral Dental Education. J Dent Educ, 2008; 72(12): 1405-1435. 24 Taylor SJ, Bogdan R. Introduction to qualitative research methods: The search for 
25 Potter WJ, Levine-Donnerstein D. Rethinking validity and reliability in content analysis.

J Applied Comm Res, 1999; 27: 258-284.

26 Holsti OR. Content analysis for the social sciences and humanities. (1969) Reading, MA:4 Addison-Wesley.

27 Hsieh H-F, Shannon SE. Three Approaches to Qualitative Content Analysis. Qual Health Res, 2005; 15: 1277-1288.

28 Denzin NK. The research act. (1984) Englewood Cliffs, NJ: Prentice Hall.

29 Kidd P, Parshall M. Getting the focus and the group: Enhancing analytical rigor in focus group research. Qualitative Health Res, 2000; 10(3): 293-308.

30 Howell WS. The Empathic Communicator. (1982) Prospect Heights, IL: Waveland Press Inc.

31 Bush HM, Schreiber RS, Oliver SJ. Failing to fail: clinicians' experience of assessing underperforming dental students. Eur J Dent Educ, 2013; 17: 198-207.

32 General Dental Council General visitation 2003-2005; General Report of the Visitors to the Undergraduate Dental Degree Programmes and Final Examinations in the United Kingdom. (2006) GDC: London

33 Henzi D, Davis E, Jasinevicius R, Hendricson W. North American dental students' perspectives about their clinical education. J Dent Educ, 2006; 70(4): 361-77.

34 Henzi D, Davis E, Jasinevicius R, Hendricson W. In the students' own words: what are the strengths and weaknesses of the dental school curriculum? J Dent Educ, 2007; 71(5): 632-45. 
35 Hendricson WD, Cohen PA. Oral health care in the 21st century: implications for dental and medical education. Acad Med, 2001; 77: 1181-206.

36 Hicks JL, Dale RA, Hendricson WD, Lauer WR. Effects of reducing senior clinical requirements. J Dent Educ, 1985; 49: 169-75.

37 Dodge WW, Dale RA, Hendricson WD. A preliminary study of the effect of eliminating requirements on clinical performance. J Dent Educ, 1993; 57: 667-672.

38 Cameron CA, Phillips SL, Chasteen JE. Outcomes comparison of solo-practitioner and group practice models. J Dent Educ, 1998; 62: 163-171.

39 Nowlin T, Dodge W, Hendricson WD. Results of a pilot patient-centered clinical education program. J Dent Educ, 1998; 62: 106(Abstract 90).

40 Evangelidis-Sakellson V. Student productivity under requirement and comprehensive care systems. J Dent Educ, 1999; 63: 407-413.

41 Holmes DC, Trombly RM, Garcia LT, Kluender RL, Keith CR. Student productivity in a comprehensive care program without numeric requirements. J Dent Educ, 2000; 64: 745754.

42 Stewart DW, Shamdasani PN. Focus groups: Theory and practice. (1990) Sage: London. 43 Smithson J. Using and analysing focus groups: limitations and possibilities. Int J Social Research Methodology, 2000; 3 (2): 103-119. 